\title{
THỰC TRANG SÂU RĂNG SỮA TRÊN TRẺ 4-6 TUỔI TẠI MộT SỐ TRƯỜNG MẦM NON Ở HÀ NộI
}

\section{Nguyễn Hà Thu* \\ TÓM TẮT. \\ Nghiên cứu thực trạng sâu răng sữa được tiến hành trên 586 trẻ 4-6 tuổi thuộc trường mầm non Hoa Hồng, trường mầm non mùng 10/10. Kết quả nghiên cứu cho thây, tỷ lệ sâu răng tạo lồ trong nghiên cứu tương đối cao (60,1\%), tỷ lệ sâu răng ở nữ cao hơn nam (khác biêt có ý nghĩa thống kê với $\mathrm{p}<0,05$ ). Tỷ lệ sâu răng cao nhất nằm ở vị trí các răng hàm hàm dưới $(31,8 \%)$ và răng cửa hàm trên $(21,1 \%)$. Chỉ số sâu mất trám của trẻ tăng dân theo lứa tuối. Chỉ số sâu mất trám chung của trẻ trong nghiên cứu là 3,79. \\ Từ khóa: Răng, sâu răng, sâu mất trám. \\ SUMMARY \\ DENTAL CARIES SITUATION OF CHILDREN AGED FROM 4 TO 6 IN SEVERAL \\ KINDERGARTENS, HANOI, VIET NAM}

The study was conducted on 586 childen at Hoa Hong kindergarten and 10/10 kindergarten, Hanoi, Viet nam. The results showed that the percentage of children suffering from tooth decay in the study was relatively high $(60,1 \%)$. A statistically difference was observed in the caries prevalence between males and females $(p<0,05)$. The high percentage of decay focused on lower molars (31,8 \%) and upper incisors (from $21,1 \%$ ). The dmft scores of childen increased with their ages. The general dmft index of childen was 3,79. teeth.

Keywords: Teeth, Decay, Decayed missing filled

\section{I. ĐĂ̆T VẤN ĐỀ}

Bệnh răng miệng đang là vấn đề sức khỏe chính của nhiều nước trên thế giới, trong đó có Việt Nam. Chi phí dành cho khám chữa răng là rất lớn, ngay ở các nước phát triển, chi phí này cũng chiếm tới $5 \%$ tổng chi phí khám chữa bệnh. Tuy nhiên, bệnh sâu răng có thể được phòng ngừa và chữa trị hiệu quả ngay từ giai đoạn sớm. Trong những năm gần đây tại Việt Nam, khi nền kinh tế phát triển, thói quen ăn uống thay đổi không hợp lý dẫn đến mức độ tăng nhanh chóng của bệnh sâu răng ngay từ hàm răng sữa của trẻ nhỏ. Đã có nhiều công trình nghiên cứu về tình trạng sâu răng tại nhiều địa phương trong cả nước cho thấy bệnh sâu răng có xu hướng gia tăng [2-5]. Để cung cấp

\footnotetext{
*Viện Đào tạo Răng hàm mặt, Trường Đại học Y Hà Nội Chịu trách nhiệm chính: Trân Thị Mỹ Hạnh

Email: tranmyhanh@hmu.edu.vn

Ngày nhận bài: 7.5.2021

Ngày phản biện khoa học: 25.6.2021

Ngày duyệt bài: 8.7.2021
}

thêm các yếu tố dich tễ về sâu răng sữa, chúng tôi nghiên cứu đề tài: "Nghiên cứu thực trạng sâu răng của trẻ mầm non 4-5 tuổi tại một số trường mầm ở Hà Nội" nhằm mục đích: tìm hiểu thực trạng sâu răng của trẻ tại khu vực nghiên cứu này.

\section{II. ĐỐI TƯỢNG VÀ PHƯƠNG PHÁP NGHIÊN CỨU}

\section{1. Đối tương nghiên cứu:}

- Tiêu chuẩn lựa chọn: toàn bộ số trẻ từ 4 6 tuổi tại trường mầm non, thành phố Hà nội 2018- 2019 có bố mẹ đồng ý hợp tác nghiên cứu được ghi nhận bằng văn bản và bản thân trẻ sẵn lòng tham gia và đủ năng lực để tham gia.

- Tiêu chuâin loại trừ: bố mẹ hoặc người giám hộ hợp pháp không đồng ý tham gia, trẻ không sẵn sàng hợp tác hoặc không đủ năng lực để hợp tác.

\subsection{Phương pháp nghiên cứu:}

2.2.1. Thiết kế nghiên cứu: nghiên cứu mô tả cắt ngang.

2.2.2. Cỡ mẫu: Nghiên cứu được tiến hành trên 586 trẻ trong độ tuổi 4-6 tại trường mầm non Hoa Hồng và Trường mầm non Mùng 10-10 đáp ứng được tiêu chuẩn lựa chọn như trền.

\subsubsection{Quy trinh và công cụ thu thập số liệu}

*Quy trinh thu thập số liệu:

- Nhận được sự thông qua đề cương nghiên cứu và sự đồng ý của Hội đồng đạo đức nghiên cứu.

- Trao đổi, giải thích và nhận được sự đồng ý tham gia nghiên cứu của trẻ và gia đình.

- Ghi chép các thông tin chung vào phiếu ghi kết quả khám răng miệng.

*Công cụ thu thập số liệu:

- Phiếu khám ghi chép các thông tin cá nhân chung và các thông tin đặc thù cho nghiên cứu: răng tổn thương, vị trí và kích thước lố sâu, giai đoạn tiêu chân răng.

- Phân loại vị trí và kích thước lỗ sâu theo phân loại Site and Size

- Dụng cụ khám cớ bản (gương, gắp, thám trâm), nạo ngà, bông.

- Áo Blouse, mũ, găng tay, khẩu trang y tế.

- Giây, bút.

*Khám và ghi nhận kêt quả:

- Điều tra viên là 5 bác sĩ răng hàm mặt đã có kinh nghiệm thực hành khám chữa bệnh răng trẻ em từ 8 đến 20 năm. Điều tra viên được tập 
huấn về cách khám và ghi chép phiếu điêuu tra.

- Mỗi trẻ được khám tuân tự tất cả các răng bởi cả hai điều tra viên. Từ đó ghi kết quả chung vào trong phiếu điêu tra. Những ca có sự khác biệt được hội chẩn lại ngay để đi tới kết luận đồng thuận giữa cả hai người khám.

- Tình trạng sâu răng của trẻ được xác định từ mức sâu răng tạo lỗ (tương ứng với mã ICDAS từ $3,4,5$ và 6 [6]) bằng gương có đèn và cây khám nha chu sau khi răng được nha sĩ lau sạch bằng bông.

Bảng 1. Tiêu chuân phát hiện sâu thân răng nguyên phát tạo lổ theo ICDAS

\begin{tabular}{|c|c|}
\hline ICDAS & Đăc điểm \\
\hline 3 & $\begin{array}{c}\text { Lỗ sâu võ men răng, } \\
\text { chưa đến ngà. }\end{array}$ \\
\hline 4 & $\begin{array}{c}\text { Bóng đen ánh lên tữ dưới ngà } \\
\text { răng }\end{array}$ \\
\hline 5 & $\begin{array}{c}\text { Lỗ sâu nhìn thấy đến lớp ngà, } \\
\text { phá hùy dưới 1/2 thân răng }\end{array}$ \\
\hline 6 & \begin{tabular}{c} 
Lỗ sâu phá vỡ quá 1/2 thân răng \\
\hline
\end{tabular} \\
\hline
\end{tabular}

Theo (WHO) để đánh giá tình trạng sâu răng trong cộng đồng, có 2 tiêu chí được sử dụng là:
- Tỷ lệ \% học sinh hiện mắc sâu răng (có ít nhất 1 răng bị sâu trên toàn bộ hàm răng) để nói lên mức độ lưu hành sâu răng ở cộng đồng.

- Chỉ số răng sâu - mất - trám dmft trung bình để nói lên nguy cơ sâu răng trong cộng đồng.

- Chỉ số sâu mất trám dmf là số răng sâu của mỗi cá thể bao gôm răng sâu chưa được xử lý, răng sâu đã hàn và răng đã mất do sâu. Chỉ số sâu mất trám trung bình được tính bằng tổng số răng sâu, răng mất do sâu và răng sâu đã trám của từng cá thể chia cho số cá thể được khám.

- Các răng không được tính bao gôm: răng chưa mọc, răng bị thiếu hoặc thửa bẩm sinh, răng bị mất không do nguyên nhân sâu răng (mất răng do chấn thương, bệnh lý nha chu, thay răng sinh lý...), răng sữa còn sót trên răng vĩnh viễn đã mọc lẫy, răng có hàn phục hồi không do sâu (răng sang chấn, trám bít hố rãnh dự phòng...).

- Các răng có lỗ sâu hoặc vừa có lỗ sâu vừa có miếng trám được tính là răng sâu. Răng bị mất do nguyên nhân sâu răng được tính là răng mất do sâu. Răng có miếng trám nhưng không có sâu răng thứ phát hoặc sâu răng tái phát đi kèm được tính là răng trám.

2.2.4. Xử lý và phân tích số liệu: Các số liệu được nhập, xử lý và phân tích theo phân mềm thống kế SPSS 16.0. Sử dụng thuật toán Chi square và so sánh các trung bình.

\section{KẾT QUẢ NGHIÊN CứU}

Sau khi thăm khám lâm sàng cho 586 trẻ tại trường mầm non Hoa Hồng và trường mâm non Mùng 10/10 tại Hà nội, chúng tôi phát hiện 352 trẻ bị sâu răng chiếm 60,1\%.

Bảng 1: Phân bố sâu răng theo theo giới

\begin{tabular}{|c|c|c|c|c|c|c|c|}
\hline \multirow{2}{*}{ Giới } & \multicolumn{2}{|c|}{ Sâu răng } & \multicolumn{2}{|c|}{ Không sâu răng } & \multicolumn{2}{|c|}{ Tống } & \multirow{2}{*}{ P } \\
\cline { 2 - 7 } & $\mathbf{n}$ & $\mathbf{\%}$ & $\mathbf{n}$ & $\mathbf{\%}$ & $\mathbf{n}$ & \\
\cline { 2 - 8 } Nam & 174 & 54,0 & 148 & 46,0 & 322 & 100 & \multirow{2}{*}{0,02} \\
\hline Nữ & 178 & 67,4 & 86 & 32,6 & 264 & 100 & $\mathbf{1 0 0}$ \\
\hline Tống & $\mathbf{3 5 2}$ & $\mathbf{6 0 , 1}$ & $\mathbf{2 3 4}$ & $\mathbf{3 9 , 9}$ & $\mathbf{5 8 6}$ & $\mathbf{1 0}$ \\
\hline
\end{tabular}

Nhận xét: Tỷ lệ trẻ nữ mắc sâu răng là $67,4 \%$ cao hơn nam (54\%), sự khác biệt này là có ý nghĩa thống kê với $\mathrm{p}=0,02$.

Bảng 2: Phân bố sâu răng theo theo tuổi

\begin{tabular}{|c|c|c|c|c|c|c|c|}
\hline \multirow{2}{*}{ Tuổi } & \multicolumn{2}{|c|}{ Sâu răng } & \multicolumn{2}{|c|}{ Không sâu răng } & \multicolumn{2}{|c|}{ Tống } & \multirow{2}{*}{ P } \\
\cline { 2 - 7 } & $\mathbf{n}$ & $\mathbf{\%}$ & $\mathbf{n}$ & $\mathbf{\%}$ & $\mathbf{n}$ & $\mathbf{\%}$ & \\
\hline 4 & 82 & 48,8 & 86 & 51,2 & 168 & 100 & \\
\hline 5 & 102 & 56,7 & 78 & 43,3 & 180 & 100 & \multirow{2}{*}{0,006} \\
\hline 6 & 168 & 70,6 & 70 & 29,4 & 238 & 100 & \\
\hline Tống & $\mathbf{3 5 2}$ & $\mathbf{6 0 , 1}$ & $\mathbf{2 3 4}$ & $\mathbf{3 9 , 9}$ & $\mathbf{5 8 6}$ & $\mathbf{1 0 0}$ & \\
\hline
\end{tabular}

Nhận xét: Tỷ lệ mắc sâu răng tăng dần theo tuối, cao nhất ở nhóm 6 tuối với tỷ lệ sâu răng là $70,6 \%$. Sự khác biệt có ý nghĩa thống kê với $p<0,05$. 
Bảng 3: Phân bố sâu răng theo vị trí răng

\begin{tabular}{|c|c|c|c|c|c|c|c|}
\hline \multirow{2}{*}{ Vùng } & \multicolumn{2}{|c|}{$\begin{array}{c}\text { Số răng có } \\
\text { Iố sâu }\end{array}$} & \multicolumn{2}{c|}{$\begin{array}{c}\text { Số răng không có } \\
\text { Iố sâu }\end{array}$} & \multicolumn{2}{c|}{ Tổng } & \multirow{2}{*}{ p } \\
\cline { 2 - 7 } & $\mathbf{n}$ & $\mathbf{\%}$ & $\mathbf{n}$ & $\mathbf{\%}$ & $\mathbf{n}$ & $\mathbf{\%}$ & \\
Răng cưa trên & 742 & 21,1 & 2774 & 78,9 & 3516 & 100,0 & \\
\hline Răng hàm hàm trên & 406 & 17,3 & 1938 & 82,7 & 2344 & 100,0 & \multirow{2}{*}{ p $<0,005$} \\
\hline Răng cửa dưới & 280 & 8,0 & 3224 & 92,0 & 3504 & 100,0 & \\
\hline Răng hàm hàm dưới & 746 & 31,8 & 1598 & 68,2 & 2344 & 100,0 & \\
\hline Tống & $\mathbf{2 1 7 4}$ & $\mathbf{1 8 , 6}$ & $\mathbf{9 5 3 4}$ & $\mathbf{8 1 , 4}$ & $\mathbf{1 1 7 0 8}$ & $\mathbf{1 0 0 , 0}$ & \\
\hline
\end{tabular}

Nhận xét: Sâu răng gặp nhiều nhất ở răng hàm hàm dưới, tiếp đó đến răng cửa trên, răng hàm hàm trền và thấp nhất ở răng cửa hàm dưới. Sự khác biệt có ý nghiia thống kê với $p<0,005$.

Bảng 4: Phân bố chỉ số dmft theo tuổi

\begin{tabular}{|c|c|c|c|c|c|c|c|}
\hline Tuối & Sâu răng & Mất răng & Trám răng & Tống & Số trẻ & dmft & P \\
\hline 4 & 230 & 0 & 6 & 236 & 168 & 1,40 & \\
\hline 5 & 602 & 0 & 14 & 616 & 180 & 3,42 & \multirow{2}{*}{$<0,005$} \\
\hline 6 & 1342 & 6 & 24 & 1372 & 238 & 5,76 & \\
\hline Tống & $\mathbf{2 1 7 4}$ & $\mathbf{6}$ & $\mathbf{4 4}$ & $\mathbf{2 2 2 4}$ & $\mathbf{5 8 6}$ & $\mathbf{3 , 7 9}$ & \\
\hline
\end{tabular}

Nhân xét: chỉ số dmft tăng dần theo tuối: dmft ở nhóm 4 tuối là 1,40 trong khi đó nhóm 5 tuối là 3,42; sang đến nhóm 5 tuổi lên tới 5,76; cao gấp 4 lân nhóm 4 tuổi. Sự khác biệt có ý nghĩa thống kê với $p<0,005$. Tỷ lệ răng được trám chiếm có 44/2224 răng tổn thương $(1,97 \%)$.

\section{BÀN LUÂN}

Kết quả nghiên cứu trong bảng 3.1 cho thây: sâu răng gặp ở trẻ nữ cao hơn trẻ nam (67,5\% và $54 \%$ ). Kêt quả nghiên cứu của nhiêuu tác giả cũng cho thấy tỷ lệ mắc sâu răng của trẻ nữ cao hơn nam: Vũ Văn Tâm năm 2017 [7] trên 690 trẻ (nữ: $73,1 \%$ > nam: 69,7\%), Nguyễn Thị Huyền Trang [8] năm 2014 trên 223 trẻ (nữ: 34,4\% > nam: $30,7 \%)$. Điều này có thể giải thích do trẻ em nữ thường ngậm cơm, ăn chậm, hay ăn vặt hơn trẻ nam nhiều nên răng dễ bị sâu hơn.

Theo phân loại mức độ sâu răng của tổ chức y tế thế giới (WHO) [9], tỳ lệ sâu răng trên $80 \%$ được đánh giá ở mức cao, từ $50 \%$ đến $80 \%$ là mức trung bình và dưới $50 \%$ là mức thấp, thì tỷ lệ sâu răng của cả 3 nhóm tuổi trong nghiên cứu của chúng tôi đều thuộc mức trung bình. Tỷ lệ mắc sâu răng trong nghiên cứu của chúng tôi $(60,1 \%)$ thấp hơn so với kết quả nghiên cứu của Vũ Văn Tâm năm 2017 (71,3\%) tại Vĩnh Phúc. Tuy nhiên vẫn còn cách xa so với mục tiêu mà WHO đã đề ra năm 2003 (tỷ lệ trẻ 5 tuổi mắc sâu răng dưới (50\%)

Tỷ lể sâu răng của trẻ trong nghiên cứu có sự thay đổi tăng dần theo độ tuổi. Nhóm 4 tuổi có tỷ lệ sâu răng thấp nhất $(48,8 \%)$, cao nhất là nhóm 6 tuổi $(70,6 \%)$. Sự khác biệt tỷ lệ sâu răng giữa các nhóm tuổi là có ý nghĩa thống kê với $\mathrm{p}$ $<0,01$. Khi trẻ càng lớn dân lên, hàm răng sữa càng tích lũy phơi nhiễm nhiều hơn với các nguy cơ gây sâu răng nên tỷ lệ sâu răng sẽ tăng. Một chiến lược giáo dục phổ biến cách chăm sóc sức khỏe răng miệng trẻ nhỏ cho các bà me từ khi mang thai và mới sinh con cũng như một chính sách chăm sóc sức khỏe răng sữa trong các trường mầm non của chính phủ là rất cấp thiết.

Chúng tôi khảo sát những răng nào là răng nhạy cảm với sâu răng nhất, có tỷ lệ sâu răng nhiều nhất, răng nào là răng ít nhạy cảm với sâu răng và có tỷ lệ sâu là thấp nhất. Kết quả bảng 3.3 cho thây: Răng hàm hàm dưới có $746 / 2344$ răng bị sâu chiếm tỷ lệ cao nhất $31,8 \%$. Tiếp theo là răng cửa trên $(21,1 \%)$, răng hàm hàm trên $(17,3 \%)$ và thấp nhất là nhóm răng cửa hàm dưới $(8,0 \%)$. Nhóm răng hàm hàm dưới mọc muộn nhất nhưng khả năng bị sâu cao nhất vì vị trí răng nằm phía dưới dễ gây đọng thức ăn đồng thời lại khó vệ sinh do trẻ không há to, dễ nôn bởi kích thích của bàn chải và kem đánh răng vào vùng răng sau dưới sát cuống lưỡi và thành họng. Vùng răng cửa dưới mọc sớm nhất nhưng ít bị sâu nhất. Điều này cảnh báo cho các bậc cha me cần chú ý kiên trì và khéo léo tạo thói quen vệ sinh răng cho con sau ăn ngay khi các răng cửa sữa vữa mọc lên trong khoang miệng bằng bàn chải đánh răng, như vậy sau 12 năm khi các răng hàm thứ nhất và thứ 2 moc lên trẻ mới dễ dàng hợp tác thuận lợi trong việc giữ vệ sinh cho vùng răng hàm này, cũng như tạo cho trẻ quen chế độ ăn ít đường và không ăn vặt.

Mức độ sâu răng của trẻ trong nghiên cứu được đánh giá thông qua chỉ số sâu mất trám (dmft). Chỉ số dmft của trẻ trong nghiên cứu được thể hiện trong bảng 3.4: Chỉ số dmft chung của trẻ trong nghiên cứu là 3,79 , tức là trung bình mỗi trẻ có gần 4 răng bị tổn thương. Trong tổng số 2224 răng đã sâu thì chỉ có 44 răng của trẻ được trám (chiếm 1,97\%). Còn lại rất nhiều 
các răng bị sâu mà không được điều trị hoặc đã trám nhưng bị sâu tái phát hoặc sâu thứ phát $(98,03 \%)$. Điều này cho thấy cha me còn ít quan tâm đến sức khỏe răng miệng của con, nhà nước cũng chưa có các biện pháp can thiệp thích đáng. Chỉ số $\mathrm{dmft}$ trong nghiên cứu tằng dần theo đô tuổi của trẻ. Ở nhóm 4 tuổi chỉ số dmft thấp nhất là 1,4 tăng dần đến nhóm 6 tuổi là 5,76 (gấp 4 lần nhóm 4 tuổi), điều này cho thây mức độ ra tăng nhanh chóng của sâu răng sữa. Chỉ số này với từng nhóm tuổi trong nghiên cứu của chúng tôi $(1,40-3,42-5,76)$ cao hơn so với kết quả của Nguyễn Văn Tâm năm 2017 tại tỉnh Vĩnh Phúc $(0,56-2,16-2,21)$, nhưng thấp hởn kết quả của Jianbo Li năm 2016 tại Quảng Đông, Trung Quốc (7,71-10,40-12,35).

\section{KẾT LUẦN}

Tỷ lệ trẻ mắc sâu răng $60,1 \%$, tỷ lệ sâu răng của nữ $(67,4 \%)$ cao hơn nam (54\%). Tỷ lệ sâu răng cao nhất nằm ở vị trí các răng hàm hàm dưới $(31,8 \%)$ và răng cửa trên $(21,1 \%)$. Chỉ số sâu mất trám của trẻ tăng theo lứa tuổi: nhóm 4 tuổi: 1,40; nhóm 5 tuổi: 3,42; nhóm 6 tuổi: 5,76. Chỉ số sâu mất trám trung bình của trẻ trong nghiên cứu là 3,79 . Răng sữa sâu được trám chiếm tỷ lệ rất thấp: 1,97\% trong tổng các răng sâu.

\section{TÀI LIÊU THAM KHẢO}

1. World Health Organization (25/3/2020) fact sheets/ Detail/ Oral health

2. Bô̂ Y tế (2001), Chiến lược quốc gia về dinh dưỡng giai đoan 2001-2010, Ban hành kèm theo Quyết định số 21/2001/QĐ-TTg, ngày 22/2/2001 của Thủ tướng chính phư, Hà Nội, tr. 12-29.

3. Trương Manh Dũng, Vũ Manh Tuấn (2011), "Thực trang bệnh răng miệng và một số yếu tố liên quan ở trẻ 4-8 tuổi tại 5 tỉnh thành của Việt Nam năm 2010", Tap chí $Y$ hoc thức hành, 797(12), tr. 56-59.

4. Vương Hương Giang (2008), Khảo sát tình trang răng miệng ở trẻ em mấu giáo lứa tuổi 4-5 tuổi, Luận văn Thạc sỹ y học, Trương Đại học Y Hà Nội, tr. 35-48.

5. Trân Văn Trường, Trịnh Đình Hải (2000), "Kết quả điều tra sức khoẻ Răng miêng toàn quốc ở Viêt Nam (1999 - 2000)", Tạp chí Y học Việt Nam, 264 (10), tr. 8-20.

6. Nigel B.'Pits (2014) ICCMS guide for Practitioners and Educators, ICCMS caries management.

7. Vũ Văn Tâm (2017), "Nghiên cứu tình trạng sâu răng của trẻ mâm non 3-6 tuổi thuộc xã Vân Xuyến, huyện Vính Tường, tỉnh Vính Phúc", tạp chí Khoa hoc đại hoc Quốc gia Hà nội: Khoa học tự nhiên và cổng ñghệ̂, taapj33, số 2S (2017) 134-139.

8. Nguyến Thị Huyến Trang (2014), "Nghiên cứu thực trạng bệnh sâu răng ở trẻ 5-6 tuổi tại trường mẩm non Xuân Nộn, huyện Đông Anh, thành phố Hà nôi", Khóa luận tốt nghiệp đại học trường Đai học Sư pham Hà nội 2 Khoa Giáo dục tiểu học.

9. World Health Organization (1994), "Oral Hygiene Indices", Oral-Health.

\title{
HIỆU QUẢ CỦA CÔNG TÁC KIỂM DICH Y TẾ BIÊN GIỚI SAU KHI SÁP NHÂ̂P TRUNG TÂM KIỂM DICH Y TẾ QUỐC TẾ VÀO TRUNG TÂM KIỂM SOÁT BẾNH TẤT
}

\begin{abstract}
Hoàng Văn Ngọc ${ }^{1}$, Trần Đắc Phu ${ }^{1}$, Nguyễn Đăng Vũng ${ }^{2}$

\section{TÓM TẮT}

Bối cảnh: Từ năm 2015, Bộ Y tế quyết định sáp nhập Trung tâm kiểm dịch y tế quốc tế (TTKDYTQT) vào Trung tâm kiểm soát bệnh tật (CDC) tỉnh/thành phố tại Việt Nam. Tuy nhiên, hiệu quả của việc sắp nhập đối với công tác Kiểm dịch y tế biên giới vẫn chưa được nghiên cứu. Muc tiều: Đánh giá hiêuu quả của công tác Kiểm dịch y tể biên giới sau khi sáp nhập TTKDYTQT vào CDC tại Việt Nam. Đối tượng và phương pháp nghiên cứu: Chúng tôi tiến hành nghiên cứu định tính, thực hiện phỏng vấn sâu với bộ câuu hỏi bán cấu trúc đối với 31 lãnh đạo Trung tâm và

\section{${ }^{1}$ Cục Y tế Dự phòng}

2 Trường Đai hoc Y Hà Nôi

Chịu trách nhiệm chính: Hoàng Văn Ngọc

Email: ngocdhy2000@gmail.com

Ngày nhận bài: 7.5.2021

lãnh đạo khoa chuyên môn tại 06 TTKDYTQT tại TP. Hà Nội, tỉnh Quảng Trị, TP. Đà Nẵng, tỉnh Kon Tum, tỉnh Đồng Nai và tỉnh An Giang từ tháng 1 năm 2019 đến tháng 8 năm 2019. Đây là các trung tâm đã thực hiện mô hình sáp nhập vào $\mathrm{CDC}$ tỉnh, thành phố. Kết quả: Sự cần thiết của việc sáp nhập TTKDYTQT vào CDC tỉnh/thành phố cho công tác Kiểm dịch y tế biên giới mang ý kiến trái chiều. Không có nhiều sự thay đổi về cơ cấu tổ chức và chức năng nhiệm vụ của Trung tâm sau khi sáp nhập. Trong khi nguồn nhân lực tại các khoa phòng tăng, số lượng cán bộ làm công tác quản trị, hành chính và chuyên môn kiểm dịch y tế biên giới giảm. Năng lực xét nghiệm tại các trung tâm được cải thiện đáng kể. Kết luận: Hiệu quả của mô hình sáp nhập TTKDYTQT vào CDC tại Việt Nam đối với công tác Kiểm dịch y tế biên giới chưa rõ ràng. Cần tiếp tưc nghiên cứu, đánh giá mô hình sáp nhập này để phát huy được điểm mạnh và khắc phục điếm han chế của mô hình.
\end{abstract}

Ngày phản biên khoa học: 28.6.2021

Ngày duyệt bài: 8.7.2021
Tư khóa: Kiểm dịch y tế biên giới, trung tâm kiểm dịch y tế quốc tế, trung tâm kiểm soát bệnh tật, sáp nhập. 